\title{
Grundtvig-litteratur 1986-1990. En bibliografi
}

\author{
Ved Aage Jørgensen
}

Nedenstående bibliografi over Grundtvig-litteratur 1986-1990 er at betragte som en videreførelse af tilsvarende bibliografier offentliggjort $i$ Grundtvig-Studier 1968, 1971, 1974, 1979 og 1984 (kumuleret udgave dækkende årene 1963-1985 - offentliggjort 1986, cf. ndf. u. I).

Stoffet er ordnet efter bibliografiske kriterier frem for efter emnekredse. Tidsrammen gælder ikke absolut, idet enkelte bidrag af ældre dato og adskillige fra begyndelsen af 1991 er medtaget. Arbejdet er afsluttet 5.6.1991.

Med hensyn til avisstoffet (artikler fortegnet ndf. u. VI, samt anmeldelser fortegnet $\mathrm{i}$ forbindelse med de arbejder, de omhandler) gælder, at bibliografien ikke gør krav på fuldstændighed. Medtaget er i alt væsentligt, hvad også Dansk artikelindeks og Dansk anmeldelsesindeks har fundet det rimeligt at redde fra glemsel.

\section{BIBLIOGRAPHICA}

Albeck, Gustav, »Indholdsoversigt og registre over Grundtvig-Studier 1968-1987«. Grundtvig-Studier, 1987 [udk. 1988], s. 65-87.

Grit, Diederik C., Dansk skønlitteratur $i$ Nederland og Flandern 17311982. Bibliografi over oversattelser og studier. 1986. S. 74-75. (Nr. 100318.)

Jørgensen, Aage, Grundtvig-litteratur 1963-1985. En bibliografi. 1986. 88 s. (Skrifter udg. af Grundtvig-Selskabet, 18.) [Rettelser hertil, cf. u. VIII.]

Jørgensen, Aage, »Tilføjelser til tre bibliografier«. Uriasposten, nr. 1, 1987, s. 18-30. (Om G s. 18-20.)

Jørgensen, Aage, Dansk litteraturhistorisk bibliografi 1967-1986. 1989. S. 212-29. (Nr. 3897-4225.) Cf. reg. s. 424.

Jørgensen, Aage, „Grundtvig-litteratur 1986-1990. Udkast til bibliografi«. Uriasposten, nr. 9, 1989 [udk. 1990], s. 19-32.

Litteraturtolkninger 1980-85. 1985. S. 114-31. 
Litteraturtolkninger 1986/1987. 1987. S. 62-64.

Nelson, Walter W., A Bibliography of Scandinavian Literature between 1760 and 1820. Lund, 1988. S. 89-93.

Spanggaard, Kristen D., Dansk skønlitteratur i fransk oversæettelse fra Middelalderen til 1975. Med et indledende afsnit omhandlende fransksprogede bidrag til den danske litteraturs historie $i$ almindelighed og $i$ enkelte tidsrum. 1988. S. 109-11. (Nr. 1372-1411.)

\section{UDGAVE}

N. F. S. Grundtvigs Praest $\varnothing$ Præedikener. I-II. Udg. af Christian Thodberg. 1988. 327, 387 s. (I: 1821, indledning s. 9-70; II: 1821-22, indledning s. 7-84.) (Anm.: Lone Fatum, Politiken 16.9.1989; Arne G. Larsen, Flensborg Avis 11.3.1989; Doris Ottesen, Kristeligt Dagblad 9.2.1989; Niels Thomsen, Preesteforeningens Blad, CXXIX, 1989, s. 609-10.)

\section{SEKUNDÆRLITTERATUR. BØGER}

Bekker-Nielsen, Tønnes, Lars Kaae, Søren Kjærsgaard Mortensen, Vagn Wåhlin \& Uffe Østergård, Stykkevis og delt. 5 essays om Grundtvig og grundtvigianisme. 1986. 144 s., 16 pl. (Indhold: VW, „Ikke stykkevis og delt«, s. 9-52; SKM, »Hvem blev inviteret til 'GiæsteBud' hos Grundtvig den 12. august 1832? «, s. 55-60; U $\varnothing$, »Den antikapitalistiske konservatisme. Jacob Christian Lindberg og den første politiske grundtvigianisme, 1839-1840«, s. 65-72; LK, »Ikkun som voxne Menneske-Børn: Grundtvig og frihed «, s. 75-122; TBN, »Skibelund krat - et grundtvigiansk nationalmonument «, s. 126-31.) (Anm.: Doris Ottesen, Kristeligt Dagblad 30.5.1986.)

Bertelsen, Otto, Dialogen mellem Grundtvig og Kierkegaard. 1990. 131 s. (Anm.: Niels Eric Grunnet, Proesteforeningens Blad, LXXXI, 1991, s. 367-70.)

Brun, Jens, Veksttanken hos Grundtvig. 1988. 88 s. (Anm.: Bent Christensen, Dansk Kirketidende, CXLI, 1989, s. 9-10.)

Christensen, Bent, Fra drøm til program. Menneskelivets og dets verdens plads og betydning i N.F. S. Grundtvigs kristendomsforståelse fra Dagnin- 
gen $i 1824$ over Opdagelsen $i 1825$ til Indledningen $i$ 1832. 1987. $324 \mathrm{~s}$. (Skrifter udg. af Grundtvig-Selskabet, 19.) (Licentiatafhandling, Københavns Universitet, 1985.) (Anm.: Jens Brun, Dansk Kirketidende, CXL, 1988, s. 79-80; P. G. Lindhardt, Jyllands-Posten 8.12.1987; William Michelsen, Grundtvig-Studier, 1988, s. 100-02; Jakob Fløe Nielsen, Fønix, XIII, 1989, s. 53-54; Doris Ottesen, Kristeligt Dagblad 5.4.1988; Kaj Thaning, Praesteforeningens Blad, LXXVIII, 1988, s. 139-44; Lene Thomsen, Debat, XIX:2, 1988, s. 15-16.)

Collins, J. E. (red.), Australian Papers on N. F. S. Grundtvig 17831872. University of Newcastle, Newcastle, N. S. W., 1983. vi, 115 s. (Indhold bl.a.: Aage Schiøler, "The Life and Times of N. F. S. Grundtvig«, s. 1-19; John S. Ryan, »The Social and Cultural Environment of N. F. S. Grundtvig«, s. 21-31; Eric J. Sharpe, »N. F. S. Grundtvig and the Danish Church«, s. 33-45; John Stanley Martin, "Grundtvig's Legacy in Modern Nordic Life«, s. 47-62; Else Christensen, „Grundtvig's Educational Philosophy«, s. 63-71; John E. Collins, »Modern Danish Folk High Schools and Grundtvig's Original Ideas«, s. 73-90.)

Engberg, Poul, Grundtvig og det folkelige oprør. 1980. $103 \mathrm{~s}$.

Florin, Vibeke, Var Grundtvig blot en gammel Nar? 1990. 48 s. (Udg. af Grundtvigs Kirkes Menighedsråd i anledning af 50-året for kirkens indvielse.)

Grell, Helge, Skaberånd og folkeånd. En undersøgelse af Grundtvigs tanker om folk og folkelighed og deres forhold til hans kristendomssyn. 1988. 346 s. (Skrifter udg. af Grundtvig-Selskabet, 20.) (Disputats [s.m. afhandling fra 1980], forsvaret på Aarhus Universitet 6.5.1988; tysk resumé s. 321-30; oppositionsindlæg m.v., cf. Schiørring, 1988, ndf.) (Anm.: Jens Brun, Dansk Kirketidende, CXL, 1988, s. 160-61 [cf. Peter Neergaard Jessen om disputatshandlingen, smst., s. 176-78]; Bent Christensen, Proesteforeningens Blad, LXXVIII, 1988, s. 730-34; Flemming Falkenberg, Debat, XIX:9, 1988, s. 34-37; Lone Fatum, Politiken 4.5.1988; Hans Kelstrup, Dansk Ungdom og Idraet, XCI:32, 1988, s. 67; P. G. Lindhardt, Jyllands-Posten 6.5.1988; William Michelsen, Grundtvig-Studier, 1989-1990, s. 308-13 [engelsk resumé, s. 332-33]; Mogens Müller, Kristeligt Dagblad 6.5.1988; Ingolf Thomsen, Flensborg Avis 4.5.1988.) (Debat: Kaj Thaning, Dansk Kirketidende, CXL, 1988, s. 414-15; Helge Grell, smst., CXLI, 1989, s. 27-28; Kaj Thaning, smst., s. 46.) 
Hansen, Kurt, N. F. S. Grundtvig. Salmebogens kampe: "Den signede dag med fryd vi ser« - historisk beskrevet. [1989.] $72 \mathrm{s.}$

Iversen, Hans Raun, And og livsform. Husliv, folkeliv og kirkeliv hos Grundtvig og sidenhen. 1987. 263 s. (Anm.: Marianne Bønløkke, Debat, XVIII:9, 1987, s. 15-20; Lone Fatum, Politiken 13.1.1988; Jørgen Gleerup, Fyens Stiftstidende 21.8.1987; Jens Ole Henriksen, Dansk Kirketidende, CXL, 1988, s. 77-78; Kjeld Holm, Aarhuus Stiftstidende 6.1.1988; Niels Højlund, Weekendavisen 11.9.1987; Bjarne Møller Jørgensen, Højskolebladet, 1988, s. 8-12; P. G. Lindhardt, JyllandsPosten 21.8.1987; William Michelsen, Grundtvig-Studier, 1987, s. 57-62; Jens Glebe Møller, Berlingske Tidende 10.11.1987; Doris Ottesen, Kristeligt Dagblad 24.9.1987.) (Debat: Kresten Drejergaard, Dansk Kirketidende, CXL, 1988, s. 268-71; Hans Raun Iversen, s. 363-64; Kaj Thaning, s. 381.)

Korsgaard, Ove, Kredsgang. Grundtvig som bokser. 1986. 158 s. (Anm.: Bjarne Nielsen Brovst, Aarhuus Stiftstidende 9.1.1987; Verner Bruhn, Dansk Ungdom og Idraet, LXXXIX, 1986, nr. 45, s. 8-9; K. E. Bugge, Grundtvig-Studier, 1987, s. 55-57; Niels Højlund, Weekendavisen 23.1. 1987; Niels Larsen, Tidens Skole, LXXXIX:1, 1987, s. 22-23; Jakob Fløe Nielsen, Centring, VII, 1986, s. 258-61; Harry Pedersen, Jydske Tidende 28.3.1987; Jens Sund, Tidsskrift for Idrat, LII:2, 1987, s. 5960.)

Schjørring, Jens Holger, Grundtvig og påsken. 1987. 166 s. (Anm.: Jens Brun, Prasteforeningens Blad, LXXVII, 1987, s. 236-39; Lone Fatum, Politiken 18.4.1987; Kjeld Holm, Fyens Stiftstidende 15.4.1987, Aarhuus Stiftstidende 15.4.1987; P. G. Lindhardt, Jyllands-Posten 7.4.1987; Mogens Müller, Kristeligt Dagblad 2.4.1987; Helge Baden Nielsen, Dansk Kirketidende, CXXXIX, 1987, s. 205-08; Jakob Fløe Nielsen, Fønix, XII, 1988, s. 61-65; Harry Nyberg, Kyrkohistorisk årsskrift, 1989, s. 188-89; Kim Arne Pedersen, Kredsen, LIV:2, 1988, s. 121-27; Regin Prenter, Dansk teologisk Tidsskrift, LI, 1988, s. 139-48; Lars Thunberg, Vår Lösen, LXXIX, 1988, s. 166-67; Johannes Værge, Weekendavisen 24.7.1987.)

Schjørring, Jens Holger (red.), Menneske først, kristen så. Helge Grells Grundtvig-disputats til debat. 1988. 101 s. (Indhold: Theodor Jørgensen, »Treenighedsteologi og folkelighed «, s. 9-25; Jens Holger Schjørring, »Den kirkelige anskuelse og det folkelige «, s. 27-37; Anders Pontoppidan Thyssen, »Det bibelsk-folkehistoriske helhedssyn «, s. 39-54 [op- 
trykt 1989, cf. ndf.]; Kaj Thaning, »Kristen først...?«, s. 55-65; Hans Raun Iversen, »Folkelighed og kristendom «, s. 67-84; Helge Grell, »Replik«, s. 85-101.) (Anm.: Bent Christensen, Dansk Kirketidende, CXL, 1988, s. 412-13.) (Debat: Kaj Thaning, Dansk Kirketidende, CXL, 1988, s. 414-15; Helge Grell, CXLI, 1989, s. 27-28; Kaj Thaning, s. 46.)

Schjørring, Jens Holger, Grundtvigs billedsprog - og den kirkelige anskuelse. 1990. 193 s. (Anm.: Johs. H. Christensen, Det fri Aktuelt 20.9.1990; Anders Rom Dahl, Debat, XXI:10, 1990, s. 14-16; Joakim Garff, Weekendavisen 28.12.1990; Niels Henrik Gregersen, Information 16.11.1990; Mogens Müller, Kristeligt Dagblad 18.9.1990; Vilhelm Nielsen, Højskolebladet, 1991, s. 69-71; Chr. U. Terp, Dansk Kirketidende, CXXXXII, 1990, s. 360-62; Niels Thomsen, Prasteforeningens Blad, LXXX, 1990, s. 705-06.)

Sorensen, Jacquelynn, Kierkegaard, Grundtvig, and Danish Literature in the Plains. Ph.D.-thesis, The University of Nebraska-Lincoln, 1984. 162 s. [Utrykt; cf. Dissertation Abstracts International, XLV A, s. 2877.]

Thodberg, Christian, Syn og sang. Poesi og teologi hos Grundtvig. 1989. 360 s. (Indhold: „En glemt dimension i Grundtvigs salmer - bundetheden til dåbsritualet «, s. 7-119 [bog, 1969]; »'Alt står i Guds Faderhånd' $\mathrm{og}$ 'Op til Guds hus vi gå'. Belyst ud fra forholdet mellem Grundtvigs prædikener og hans salmer i sommeren 1856 «, s. 120-38 [1971]; »Omkring Sangværkets første bind 1836-37«, s. 139-72 [1975]; »Digtet 'De Levendes Land' belyst ud fra Grundtvigs prædikener og den bibelske poesi «, s. 173-209 [1984]; »Om 'Gud Helligånd, vor trøstermand'«, s. 210-24 [1976]; »En kvindesalmes historie«, s. 225-41 [1979]; "Grundtvigs skovoplevelse i 1811 og prædikenerne over Peters fiskedræt i tiden, der fulgte«, s. 242-95 [1987]; "Var Grundtvigs nadversyn luthersk? «, s. 296-324 [1975]; »Den grundtvigske arv: Christian Hostrup som prædikant med særligt henblik på de grundtvigske elementer «, s. 325-59 [1977].) (Anm.: Lone Fatum, Politiken 16.9.1989; Marianne Frank Larsen, Debat, XX:4, 1989, s. 22-26; Jan Lindhardt, Berlingske Tidende 30.3.1989; Steffen Kjeldgaard-Pedersen, Kristeligt Dagblad 7.2.1989; Niels Thomsen, Praesteforeningens Blad, LXXIX, 1989, s. 95-99.)

Thomsen, Preben (red.), Grundtvigs Kirke 1990. Udg. af Grundtvigs Kirkes Menighedsråd. 1990. 80 s. (Indhold bl.a.: Kaj Thaning, »Grundtvig«, s. 11-18 [efterfulgt af oversættelser til engelsk, fransk og tysk].) 
Thyssen, Anders Pontoppidan, Grundtvig og den grundtvigske arv. Afhandlinger. Udg. af Jakob Balling, Hans Raun Iversen, Jens Holger Schjørring og Christian Thodberg. 1991. vi, 397 s. (Skrifter udg. af Grundtvig-Selskabet, 22.) (Udg. til forf.'s 70-årsdag 17.7.1991; indhold bl.a.: »Grundtvigs tanker om kirke og folk «, s. 3-142 [1983]; »'Menneske først - '. Om Kaj Thanings Grundtvig-disputats «, s. 143-86 [1963]; »Det bibelsk-folkehistoriske helhedssyn «, s. 187-202 [1988; om Helge Grells Grundtvig-disputats]; »Bibliografi«, s. 387-97.)

Yde, Henrik, Før selv de mindste af de små får del i livets gloede ... Grundtvigsk folkeoplysning og socialistisk arbejderbevogelse - et historisk rids. 1987. 53 s. (Temanummer af Tryk.) (Se spec. s. 5-11.) (2. udgave, 1988; 60 s. [med tilføjelser: rettelsesliste s. 54, "politisk efterskrift «, s. 55-58 og personregister s. 59-60].) (Anm.: William Michelsen, Grundtvig-Studier, 1987 [udk. 1988], s. 62.)

Aasen, Kirsti, Alle mine kilder. Oslo, 1986. 127 s. (Anm.: Helge Baden Nielsen, Grundtvig-Studier, 1986, s. 91-93.)

\section{SEKUNDAERITTERATUR. DELE AF BøGER}

Andersen, Poul E., "Folkelighed og vulgaritet «. I: Steffen Johannessen \& Torben Krogh (red.), Livsoplysning. Festskrift til K. E. Bugge $i$ anledning af 60-års fødselsdagen den 4. oktober 1988. 1988. S. 13-24, spec. s. 14-17.

Bang, Ole, Store Hans Christian. H. C. Ørsted 1777-1851. 1986. 174 s. (Heri s. 57-61 afsnittet »Hvem er den falske profet? « [om konfrontationen i 1814 efter Ø's anmeldelse af »Verdens Krønike«].)

Bjørn, Claus, Gyldendals og Politikens Danmarkshistorie. X: Fra reaktion til grundlov, 1800-1850. 1990. S. 271-82 (dvs. afsnittet »Grundtvig og grundtvigianismen $\ll)$. Cf. reg.

Brovst, Bjarne Nielsen, »Gunderslevholm «/» Rønnebæksholm«. I hans: Fra Himmerland til Farøerne. Rejsekrøniker. 1990. S. 125-31, 132-38.

Christensen, Johs. H., »Vejen til Vartov. En reportage«. I: Thorkild Grosbøll, Bent Hahn \& Steffen Kjeldgaard-Pedersen (red.), Teologi og tradition. Festskrift til Leif Grane 11. januar 1988. 1988. S. 213-31. (Også i: Vartovbogen, 1988, s. 119-38.) 
Elbek, Jørgen, »Mytologen Grundtvig«. I hans: Fundet og søgt. Artikler om digtere. 1986. S. 12-24.

Elbek, Jørgen, "Sprog og natur «. I: Svend Andersen (red.), Naturens bog. 1986. S. 102-16. (Complementa, 2.) (Om G spec. s. 108 og 11013.)

Elbek, Jørgen, »Frederik og Ulrikke«. I hans: Moder, søster, elskte ... Fire artikler. [1989.] S. 31-36. (Om G og den ældre søster.)

Engberg, Poul, Grundtvig og det nye Europa. 1990. 60 s. (Debatbog; heri s. 18-23 om G's folkelige historiesyn.)

Gjesing, Knud Bjarne, »Historie og identitet - belyst gennem N. F. S. Grundtvigs 'Nyaars-Morgen'«. I: Finn Hauberg Mortensen \& Povl Schmidt (red.), Profiler. Nordisk Institut 1966-86, Odense Universitet. 1986. S. 107-17.

Grosbøll, Thorkild, »Sammenbrud og suverænitet - et forsøg på en bestemmelse af 'det folkelige' «. I: Thorkild Grosbøll, Bent Hahn \& Steffen Kjeldgaard-Pedersen (red.), Teologi og tradition. Festskrift til Leif Grane 11. januar 1988. 1988. S. 288-300. (Bl.a. om G.)

Halvorsen, Erik, Forfattere $i$ deres samtid. Dansk litteraturhistorie fra Holberg til idag. 1988. S. 25-27.

Hauge, Hans, Dekonstruktiv teologi. Tekster på kanten af det religiøse og det littercere. 1986. 191 s. (Heri afsnittene »Kierkegaard og Grundtvig«, s. 52-54, og »Det levende ord som død skrift«, s. 135-50; cf. reg.) (Anm.: Rudolph Arendt, Dansk Kirketidende, CXXXIX, 1987, s. 4246.)

Hauge, Hans, »Grundtvigs mislæsning af Kingo. Et Bloomsk forsøg«. I: Lars Erslev Andersen, Per Stounbjerg, Peter Brix Søndergaard \& Erik Østerud (red.), Løjper. Temaer i aktuel tekstloesning. 1988. S. 23-37 (+ tekster s. 37-41).

Henriksen, Aage, »Nyaars-Morgen - vandskellet i Grundtvigs forfatterskab«. I hans: Svanereden. Essays/Foredrag/Debat. Red. af Flemming Ettrup og Jørgen I. Jensen. 1990. S. 115-33. (Optryk af bidrag til Gbibliografiens nr. 49.) (Smst. s. 134-39: „Kunne Grundtvig læse? «, et debatindlæg bl.a. med inddragelse af $\mathrm{G}$ som tekstlæser; < Information 
28.10.1985.) (Cf. Jørgen Hunosøe, »Den varige lyst«, Bogens Verden, 1990, s. $405-14$, spec. s. 410 .)

Höger, Alfons \& Fritz Paul, „Nikolaj Frederik Severin Grundtvig«. I: Walter Jens (red.), Kindlers neues Literatur Lexikon. VI: Ga-Gr. München, 1989. S. 955-57. (Om »Nordens Mytologi«, »Nyaars-Morgen« og „Sang-Værk til den danske Kirke«.)

Jensen, Niels Lyhne, »Romantik i Grundtvigs 'Nordens Mytologi' 1808 «. I: Oskar Bandle, Jürg Glauser, Christine Holliger \& HansPeter Naumann (red.), Nordische Romantik. Akten der XVII. Studienkonferenz der International Association for Scandinavian Studies 7.-12. August 1988 in Zürich und Basel. Basel/Frankfurt a.M., 1991. S. 20513. (Beiträge zur nordischen Philologie, 19.)

Jørgensen, Sven-Aage, "Lessing in Dänemark. Auseinandersetzungen zwischen Grundtvig und Kierkegaard «. I: Wilfried Barner \& Albert M. Reh (red.), Nation und Gelehrtenrepublik. Lessing im europäischen Zusammenhang. Detroit/München, 1984. S. 315-24. (= Lessing Yearbook, Sonderband.)

Jørgensen, Theodor, „Schleiermachers und Grundtvigs Verständnis vom Heil in Bezug auf die Versöhnungslehre unter besonderer Berücksichtigung ihrer Bestimmung des Bösen«. I: Helge Hultberg, m.fl. (red.), Schleiermacher im besonderer Hinblick auf seine Wirkungsgeschichte in Dänemark. Vorträge des Kolloquiums am 19. und 20. November 1984. Kopenhagen/München, 1986. S. 82-101. (Text \& Kontext, Sonderreihe, 22.)

Kampp-Olsen, Otto, 1800-tallets litteratur. 1988. S. 10-14.

Kirmmse, Bruce H., Kierkegaard in Golden Age Denmark. Bloomington/Indianapolis, 1990. xiv, 558 s. (Om G s. 198-237, dvs. kapitlet »N. F. S. Grundtvig and History's Flock: National Popular Culture in the Service of Religion «, hvortil noter s. 505-08; cf. reg.)

Klein, Birgit, »Nogle danske digtere «. I hendes: Jorden dør uden karlighed. Et bidrag fra den lyse del af den åndelige verden om karlighed og seksualitet. 1983. S. 66-80. (Om G s. 69-73.)

Klysner, Finn, Tat på litteraturhistorien. 1988. S. 45-47. (For folkeskolens ældste klasser.) 
Kofoed, Niels, »N. F. S. Grundtvig«. I hans: Littercere skaebnetydninger. Nogle forelaesninger $i$ dansk litteratur. 1989. S. 7-36.

Lauring, Palle, „Forfatternes vildelser «. I hans: Ordet der blev borte og andre essays. 1984. S. 71-98, spec. s. 77-80.

Lausten, Martin Schwarz, Danmarks kirkehistorie. 1987. 2. udg., 1989. S. 216-29 (dvs. kapitlet »N. F. S. Grundtvig«).

Lundgreen-Nielsen, Flemming, »Hoved-Strømninger. N. F. S. Grundtvigs og Georg Brandes' historieskrivning «. I: Erland Kolding Nielsen, Jesper Düring Jørgensen \& Erik Dal (red.), Bøger/biblioteker/mennesker. Et nordisk festskrift tilegnet Torben Nielsen, Universitetsbiblioteket $i$ København. 1988. S. 497-517.

Lönnroth, Lars, „The Academy of Odin. Grundtvig's Political Instrumentalization of Old Norse Mythology «. I: Gerd Wolfgang Weber (red.), Idee/Gestalt/Geschichte. Festschrift Klaus von See. 1988. S. 33954.

Molland, Einar, Norges kirkehistorie $i$ det 19. århundre. I-II. Oslo, 1979. I s. 115-45 (dvs. kapitlet "Grundtvigiansk kirkelighet og kirkekamp«), 266-311 (dvs. kapitlet »Kampen om grundtvigianismen«). Cf. reg.

Mortensen, Viggo, Teologi og naturvidenskab. Hinsides restriktion og ekspansion. 1989. 378 s. (Disputats, forsvaret på Aarhus Universitet 17.3.1989.) (Heri s. 287-89 om G.) (Anm.: William Michelsen, Grundtvig-Studier, 1989-1990, s. 304-08 [engelsk resumé s. 333-34].)

Møllehave, Johannes, „Grundtvig som konkretist«. I hans: Laesehest med versef $\varnothing d d e r$. Fra folkevisen til den folkelige vise. 1986. S. 121-29.

Nielsen, Erik A., "Sangværk til den danske kirke. Fortællingen om en titel«. I: Thorkild Grosbøll, Bent Hahn \& Steffen Kjeldgaard-Pedersen (red.), Teologi og tradition. Festskrift til Leif Grane 11. januar 1988. 1988. S. $194-212$.

Nielsen, Erling, »Grundtvig og Norge«. I hans: Vor mand $i$ Oslo. En tekst-mosaik. 1990. S. 87-110. (Optryk af efterskrift til G-bibliografiens nr. 109.) 
Nielsen, Vilhelm, »Tale og Skrift. Grundtvigs selvopgør i 1838«. I: Steffen Johannessen \& Torben Krogh (red.), Livscplysning. Festskrift til K. E. Bugge $i$ anledning af 60-års fødselsdagen den 4. oktober 1988. 1988. S. 25-36.

Pedersen, Poul, „Grundtvig i verdenshistorien og blandt fremmede folk«. I: Ole Høiris (red.), Dansk mental geografi. Danskernes syn på verden - og på sig selv. 1989. S. 26-34.

Petersen, Teddy (red.), Skrivefrakhed. 1989. 494 s. (Studier i Skandinavistik, 3.) (Heri s. 175-238 om G.) [Fremstillingen udgør 2. del af projektet $»$ Fra fiskalhermeneutik til andre forebyggende forholdsregler. Aspekter af censurens historie i Danmark 1770-1849 « og er skrevet af Hella van Donk, Erik Paul Madsen og Teddy Petersen.]

Riis, Ricardt, Myte og rationalitet. En Grundtvig-inspireret bedømmelse af Jürgen Habermas. 1988. 209 s. (Folkelig teologi, 4.) (Heri s. 19-26 om G's historiesyn.)

Simon, Erica, » - og solen står med bonden op - «. De nordiske folkehøjskolers idéhistorie. 1989. 169 s. (Heri: "Danmark «, s. 9-53 [om G spec. s. 12-27].) (Anm.: Søren Ehlers, Uddannelseshistorie, XXIII, 1989, s. 143-44; Poul Haahr, Dansk Kirketidende, CXLI, 1989, s. 187-89.)

Skydsgaard, Niels Jørgen, »Se, hvilken morgenstund. Refleksioner over fire danske morgensalmer [af Kingo, Grundtvig, Ingemann og Jakob Knudsen]«. I: Thorkild Grosbøll, Bent Hahn \& Steffen KjeldgaardPedersen (red.), Teologi og tradition. Festskrift til Leif Grane 11. januar 1988. 1988. S. 182-93.

Slumstrup, Finn, »1983 og de kommende grundtvigske kampår«. I hans: Vallekilde Jerusalem. Replikker fra den danske rejse i firserne. 1989. S. 19-24. (< Kristeligt Dagblad 31.12.1982.) (Cf. essayet »Vallekilde«, spec. s. 9-12 [om »Nyaars-Morgen «].)

Smith, C. Howard, Scandinavian Hymnody from the Reformation to the Present. Metuchen, N.J./London, 1987. S. 122-29.

Thodberg, Christian, »Nikolaj Frederik Severin Grundtvig «. I: Theologische Realenzyklopädie. XIV: Gottesdienst-Heimat. Berlin/New York, 1985. S. 284-89. 
Thodberg, Christian, „En kvindesalmes historie«. I: Mette Müller (red.), Festskrift Henrik Glahn. 1919 - 29. maj - 1979. 1979. S. 69-86. (Om »Med sin Alabaster-Krukke« og det græske forlæg.)

Thodberg, Christian, »Grundtvigs bibelsyn «. I: Sigfred Pedersen (red.), Skriftsyn og metode. Om den nytestamentlige hermeneutik. 1989. S. 12642.

Thyssen, Anders Pontoppidan, "Menneskesyn, poesi og kirkesyn hos N. F. S. Grundtvig «. I: Menneskesynet. 1989. S. 170-87.

Thyssen, Anders Pontoppidan, "Folkekirkens forhold til andre kirkesamfund historisk belyst «. I: Peder Nørgaard-Højen, Hans Raun Iversen, Johs. Langhoff \& Peter Lodberg (red.), På enhedens vej. [Bidrag til den фkumeniske bevcegelses historie $i$ Danmark $i$ det 20. århundrede.] 1989. S. 13-21, spec. s. 15-17.

Wentzel, Knud, Utopia. Et motiv i dansk lyrik. 1990. 347 s. (Disputats, forsvaret på Københavns Universitet 1.6.1990.) (Heri s. 81-87 om »Riim-Brev til nordiske Paarørende «, s. 118-22 om »Velkommen igjen, Guds Engle smaa «, s. 128-30 om »Kirken det er et gammelt Huus«, s. 130-32 om »Som Foraars-Solen morgenrød « og s. 197-205 om »De Levendes Land«; cf. reg.)

Winterhager, Jürgen Wilhelm, »Møde med Grundtvig - træk af hans levnedsløb og nogle personlige oplevelser «. I: Eskild Rousing Kraglund (red.), Vor kirke i Berlin. 1987. S. 140-46.

\section{SEKUNDARLITTERATUR. TIDSSKRIFTARTIKLER}

Adriansen, Inge, »Mor Danmark. Valkyrie, skjoldmø og fædrelandssymbol«. Folk og Kultur, 1987, s. 105-63, spec. s. 108-12 (dvs. afsnittet $»$ Fædrelands-allegorier i litteraturen frem til $1850 \ll)$.

Albeck, Gustav, »Har Grundtvig-Selskabet fors $\emptyset \mathrm{mt}$ digteren Grundtvig?« Grundtvig-Studier, 1987 [udk. 1988], s. 29-44. (Engelsk resumé, smst., 1988, s. 109-10.)

Allchin, A. M., »Grundtvig set fra England «. Dansk Kirketidende, CXL, 1988, s. 376-79. 
Allchin, Arthur Macdonald, "Grundtvig Seen in Ecumenical Perspective «. Grundtvig-Studier, 1989-1990, s. 105-20. (Dansk resumé, s. 32526.)

Andersen, Kristen Erik, »'Det grundtvigske kun' - et forsinket notat til en verslinie «. Dansk Kirketidende, CXL, 1988, s. 172-74. (Debat: Allan Pedersen, s. 229-30; Kristen Erik Andersen, s. 262-63.)

Balling, Jakob, "En sang. Om 'Moders navn er en himmelsk lyd'«. Dansk Kirketidende, CXXXIX, 1987, s. 277-78.

Balslev-Clausen, Peter, »Da vandre Guds engle op og ned - om englene i Grundtvigs julesalmer «. Gloedelig Jul (udg. af Kirkeligt Samfund), 1982, s. 8-18.

Balslev-Clausen, Peter, »'Mødrene-arv fra Paradis'. Om Grundtvigs kvindesalmer i 'Den danske Salmebog'«. Prasteforeningens Blad, LXXVII, 1987, s. 381-94.

Balslev-Clausen, Peter, „Verdenssyn og menneskesyn i Grundtvigs salmedigtning «. Grundtvig-Studier, 1989-1990, s. 46-65. (Licentiatforelæsning holdt på Københavns Universitet 24.2.1989; engelsk resumé, s. 323-24.)

Bartholin-Jørgensen, P. H., »Skal den Lutherske Reformation virkelig fortsættes?«Vartovbogen, 1989, s. 20-31.

Bartholin-Jørgensen, P. H., »Grundtvig og folkekirken «. Dansk Kirketidende, CXLI, 1989, s. 348-51 og 362-65.

Bertelsen, Otto, »Grundtvig og Kierkegaard«. Proesteforeningens Blad, LXXVI, 1986, s. 509-22.

Bertelsen, Otto, „Grundtvigs og Kierkegaards syn på statskirken «. Dansk Kirketidende, CXXXVIII, 1986, s. 289-90.

Bertelsen, Otto, »Grundtvig og Kierkegaard om menneskekundskab «. Dansk Kirketidende, CXXXIX, 1987, s. 130-32.

Bjørn, Lars Thorkild, "Havde jeg tjent en tønde guld... eller 'Skolen for livet'«. Dansk Kirketidende, CXL, 1988, s. 154-57. 
Bojsen-Møller, Anna, »Eline Boisens syn på Grundtvig og den første generation af grundtvigske abekatte«. Vartovbogen, 1987, s. 62-82.

Bording, Frede, »Moses’ sang«. Højskolebladet, 1989, s. 133-37. (Om »Arildstiden kom i hu«.)

Bradley, S. A. J., "Grundtvig, Anglo-Saxon Literature, and 'Ordets Kamp til Seier'«. Grundtvig-Studier, 1989-1990, s. 216-45. (Dansk resumé, s. 330.)

Brandt-Nielsen, E., »Lise Blicher, Grundtvigs første hustru«. Dansk Udsyn, LXVII, 1987, s. 185-97.

Bredsdorff, Poul, »En salme«. Dansk Kirketidende, CXXXIX, 1987, s. 261-62. (Om »Apostlene sad i Jerusalem «; hertil Clemens Barfod s. 293-94.)

Brun, Jens, »Myte og fortælling«. Under Guds Ord, nr. 268, 1984, s. 14.

Bugge, K. E., »Grundtvig and India«. Bangalore Theological Forum, XVII:2, 1985, s. 49-60. $\left({ }^{*}\right)$

Carlsen, Jørgen, »Grundtvig, PH og lidt om abekatte«. Højskolebladet, 1987, s. 136-38.

Christensen, Bent, "'Nyaars-Morgen' som teologisk og kirkehistorisk dokument «. Proesteforeningens Blad, LXXVII, 1987, s. 3-9.

Christensen, Bent, »Grundtvig og naturvidenskaben«. Dansk Kirketidende, CXLI, 1989, s. 216-18.

Christensen, Bent, „Var Grundtvigs nyerkendelse i 1832 en tragisk hændelse?« Grundtvig-Studier, 1989-1990, s. 16-31. (Licentiatforelæsning holdt på Københavns Universitet 19.11.1985; engelsk resumé, s. 316-19.)

Christensen, Johs. H., „Vejen til Vartov. En reportage«. Vartovbogen, 1988, s. 119-38. (Også i festskriftet til Leif Grane, cf. ovf.)

Damsholt, Torben, »Også et jubilæum«. Højskolebladet, 1988, s. 62224. (150-året for »Mands Minde«-foredragene.) 
Degn, Christian, „Freundfeindliche Vettern«. Rendsburger Jahrbuch, XXXVII, 1987, s. 10-22. (Om Henrich Steffens og G, Orla Lehmann og Theodor Lehmann.)

Del Zanna, Lorenzo, »Un precursore dell'educazione permanente. Nikolaj Frederik Severin Grundtvig (1783-1872)«. La civiltà cattolica, CXXXV:3, 1984, s. 209-24.

Dissing, Jette, »Til skolebrug eller kirkebrug? To af Grundtvigs bibelhistoriske digte «. Vartovbogen, 1989, s. 33-51. (Om »De Vise fra $\varnothing$ sten $«$ og »Syndfloden $\ll$.

Ditlevsen, Kirsten, »Grundtvig og jomfru Maria«. Højskolebladet, 1990, s. 729-34. (Cf. hertil: Ulrik Dybdal, "Grundtvig, Maria og Kirken«, smst., 1991, s. 41-42.)

Elbek, Jørgen, »Olympen, Grundtvig og [Villy] Sørensen. Et foredrag «. Dansk Udsyn, LXIX, 1989, s. 340-57.

Elbek, Jørgen, »Fantasiens naturhistorie«. Fønix, XIV, 1990, s. 222-36. (Især om G.)

Engberg, Poul, „Gudernes Gud - eller præsternes?« Højskolebladet, 1986, s. 648-50. (Om G’s angreb på teologisk rationalisme.)

Engberg, Poul, »Myten om Danmark«. Dansk Kirketidende, CXL, 1988, s. 254-56. (Bl.a. om Kong Skjold-digtet.)

Engberg, Poul, »Skal teologien herske over højskolen?« Højskolebladet, 1989, s. 197-99. (Sammenligning af Kaj Thanings og Helge Grells Gtolkninger.) (Cf. Sigrid Bennike, smst., s. 274 og 285.)

Fleinert-Jensen, Fl., »Nikolaj Frederik Severin Grundtvig et la tradition byzantine«. Irénikon (Chevetogne), LX, 1987, s. 163-76.

Furre, Berge, »Grundtvigianarar i den norske kyrkje. Forsøk på eit historisk perspektiv«. Kirke og Kultur, XC, 1985, s. 130-47.

Gjesing, Knud Bjarne, »Narcissisme, forelskelse - og Grundtvig «. Kredsen, LV:1, 1989, s. 7-19.

Gleerup, Jørgen, „Grundtvig og erhvervslivet. 'Åndens løsen er bedrifter'«. Dansk Kirketidende, CXL, 1988, s. 10-12. 
Grell, Helge, »Det nationale og det folkelige«. Vartovbogen, 1990, s. $39-48$, spec. s. $46-48$.

Hansen, Niels Buur, »... og du hører dens susen «. Højskolebladet, 1990, s. 198-202 og 214-19. (1. del om G's opfattelse af mennesket som guddommeligt eksperiment af ånd og støv.)

Harder, Peter, »Grundtvig og nutidens skoleproblemer«. Dansk Kirketidende, CXXXVIII, 1986, s. 88-92.

Hartshorne, M. H., »Grundtvig og Lincoln «. Dansk Udsyn, LXVIII, 1988, s. 42-52.)

Henriksen, Jens Ole, »Gud, Grundtvig og det danske folk«. Arrhus Stift, XXVI, 1988, s. 37-42.

Holm, Preben, „Grundtvig og Luther - en sammenligning af temaer i deres teologi «. Præesteforeningens Blad, LXXVII, 1987, s. 69-80.

Høirup, Henning, »Omkring Grundtvig-Selskabets tilblivelse «. Grundtvig-Studier, 1987 [udk. 1988], s. 45-54. (Engelsk resumé, smst., 1988, s. 110-12.) (Foredrag holdt ved Grundtvig-Selskabets årsmøde 15.1.1988.)

Højlund, Niels, »Vi synger nr. 138, 'Jeg kender et land'«. Højskolebladet, 1991, s. 261-62.

Haarder, Andreas, »En sang. Sang i det Grønne«. Dansk Kirketidende, CXXXIX, 1987, s. 195-97.

Iversen, Hans Raun, »Ånd og livsform «. Tidsskriftet Den fri Loererskole (Ollerup), XXXVI:2, 1988, s. 19-23.

Jensen, Jørgen I., [Anmeldelse af G-bibliografiens nr. 39 og 109.] Scandinavica, XXV, 1986, s. 231-34.

Jensen, Jørgen I., »Kirkesangsproblemer «. Fønix, X, 1986, s. 184-88. (Anmeldelse af G-bibliografiens nr. 92 og 926.)

Jørgensen, Theodor, »Adskillelse og vekselvirkning. Om Grundtvigs syn på folkelighed og kristendom«. Grundtvig-Studier, 1986, s. 71-83. (På tysk: "Volkstum und Christentum bei N. F. S. Grundtvig. Unterscheidung und Wechselwirkung «. Kerygma und Dogma, XXXIII, 
1987, s. 192-206. [„Eine für deutsche Verhältnisse überarbeitete Fassung...«.])

Jørgensen, Theodor, „Teologi mellem forkyndelse og videnskabelighed «. Norsk teologisk Tidsskrift, LXXXVII, 1986, s. 65-80. (Om Svein Aage Christoffersens "Identifikasjon og verifikasjon. En studie i Gerhard Ebelings fundamentalteologi«, 1984; G inddrages s. 75-77.)

Kloster, Flemming, »Narcissisme og kærlighed: Grundtvigs usædvanlige læreproces«. I fiskens tegn, nr. 5, 1986, s. 3-9.

Kozu, Haruo, »Guruntowi to angurosakuson kenkyu «. Kansai gaikokugo daigaku kenkyu ronshu, nr. 40, 1984, s. 71-83. (*)

Kvist, Vagn, »Grundtvig og Naturalisterne. Et foredrag«. Fønix, IV, 1980, s. 306-20.

Kühnhold, Christa, „Grundtvig und Kierkegaard als Grundleger eines modernen sozialen Bewusstseins «. Grundtvig-Studier, 1988, s. 60-75. (Bemærkninger hertil af William Michelsen s. 76-80; dansk version af artiklen s. 81-95 og af bemærkningerne s. 96-99.)

Lyster, Jens, „Om Grundtvigs 'Sov sødt, Barnlille' og andet godt i en upåagtet bønnebog fra 1847 «. Hymnologiske Meddelelser, XVIII, 1989, s. 139-66. (Anm.: Gustav Albeck, Grundtvig-Studier, 1989-1990, s. 31415.)

Löfström, Inge, »Grundtvig kom aldrig till Sverige«. Vår lösen, LXXVIII, 1987, s. 124-31.

Michelsen, Signe, »Grundtvig på grønlandsk «. Grundtvig-Studier, 1986, s. 87-90. (Engelsk resumé s. 105.) (Anmeldelse af Frederik Nielsen, $N$. F. S. Grundtvigip tussiusiai, kalaallisuunngortitat, Nuuk 1985; 49 s. [30 salmer i oversættelse med forord af Aqigssiaq Møller og FN, s. 3-6.])

Michelsen, William, »Om Grundtvigs tænkning og den nyere tids filosofi. Introduktion til 'Danne-Virke', II«. Grundtvig-Studier, 1986, s. 5670. (Engelsk resumé s. 99-102.) (Cf. forf.'s »Introduktion til 'DanneVirke'«, smst., 1985, s. 67-78.)

Michelsen, William, »Om Grundtvigs menneskesyn «. Grundtvig-Studier, 1987 [udk. 1988], s. 16-28. (Engelsk resumé, smst., 1988, s. 107-09.) (Foredrag holdt ved Grundtvig-Selskabets årsmøde 15.1.1988.) 
Michelsen, William, »Grundtvig-myten og forskningen «. Grundtvig-Studier, 1988, s. 103-06. (Anmeldelse af »Vartovbogen «, 1987 og 1988.) Nielsen, A. Strange, »En salme: 'De levendes land'«. Dansk Kirketidende, CXXXIX, 1987, s. 132-33.

Nielsen, Helge Baden, „Grundtvig og Norge - om et nybrud i norsk kirkeliv«. Vartovbogen, 1987, s. 83-96.

Nielsen, Helge Baden, „Et skabelsesteologisk perspektiv på 'DanneVirke' «. Grundtvig-Studier, 1988, s. 44-59. (Foredrag holdt ved Grundtvig-Selskabets årsmøde 14.1.1988; engelsk resumé s. 112-14.)

Nielsen, Helge Baden, „Grundtvig og Den danske Forening«. Dansk Kirketidende, CXXXXII, 1990, s. 272-81. (Foredrag holdt i Grundtvigsk Konvent af 1916; cf. hertil replik af Niels Jacob Carstens, s. 315-16.)

Nielsen, Jakob Fløe, »Kristologien i Grundtvigs salmer«. GrundtvigStudier, 1989-1990, s. 121-40. (Engelsk resumé, s. 326.)

Nielsen, Jakob Fløe, »Det underbevidste set fra en prædikestol. Hvad har den kristne forkyndelse at sige til de længsler og drømme, der rører sig i os? «Vartovbogen, 1990, s. 119-28.

Nielsen, Paul Zebitz, „Glemt Grundtvigbog i Præstø Præstegård. 10 præster har passet på Grundtvigs originale prædikenreferater i 166 år«. Roskilde Stiftsblad, XXXIX, 1988, s. 132-37.

Nielsen, Vilhelm, „Tre-fire gange N. F. S.«. Højskolebladet, 1988, s. 625-30. (Om G-bøger af Helge Grell, Bent Christensen, Hans Raun Iversen og Hans Hauge.)

Nielsen, Vilhelm, »Omkring Grundtvigs 'Paaske-Lillien'«. Dansk Udsyn, LXX, 1990, s. 253-68.

Noack, Bent, »Den oldengelske digtning og Grundtvig «. Grundtvig-Studier, 1989-1990, s. 141-56. (Engelsk resumé, s. 327.)

Nägele, Horst, „Dänemark geistesgeschichtlich ein Problem Deutschlands? Betrachtungen mit besonderer Berücksichtigung der zu dem Überbaucharakter von Nationalsprachen kritischen Positionen N. F. S. Grundtvigs von 1815 und Jens Baggesens von 1824«. Schleswig-Holstein, XXIV, 1972, s. 101-04. 
Nørfelt, Henrik Fibiger, „Fire hidtil utrykte Grundtvig-breve - til belysning af Grundtvigs forhold til C. E. F. Weyse, Hans MatthisonHansen og Cora Nyegaard «. Hymnologiske Meddelelser, XV, 1986, s. 42-59.

Olafsson, Felix, »Grundtvigs brev til Det britiske og udenlandske Bibelselskab. Et brev om Lindbergs bibeloversættelse og om apokryferne «. Kirkehistoriske Samlinger, 1985, s. 145-50. (Brev af 17.5.1837.)

Otzen, Benedikt, »Kult und Mythos im Alten Testament aus skandinavischer Sicht «. Kerygma und Dogma, XXXV, 1989, s. 23-33. (Om G s. 24-26.)

Paludan, Lars, »Grundtvig i Köln«. Dansk Kirketidende, CXL, 1988, s. 379-80. (Om G-kongres i Köln 7.-10.9.1988.)

Pedersen, Kim Arne, „Grundtvigs natursyn«. Grundtvig-Studier, 19891990, s. 66-104. (Engelsk resumé, s. 324-25.)

Prenter, Regin, „Gjorde Grundtvig op med den lutherske nadverlære? «. Praesteforeningens Blad, LXXVII, 1987, s. 153-68. (Debatindlæg af Christian Thodberg s. 769-76 og af Leif Kallesen s. 776-84.)

Rasmussen, Anton, "Han udgav Grundtvigs sangværk. Seminarieforstander Jens Chr. Madsen fra Sahl«. Hardsyssels Arbog, 2. rk., XXIII, 1989, s. 69-74.

Rasmussen, Peter Martin, „Den grundtvigske arv på Færøerne «. Grundtvig-Studier, 1989-1990, s. 187-215. (Engelsk resumé, s. 329.)

Reich, Ebbe Kløvedal, „Grundtvig i mands minde - en dialogforelæsning 150 år senere «. Vartovbogen, 1989, s. 7-18.

Röhrig, Paul, "Grundtvigs betydning for den tyske voksenuddannelse«. Dansk Udsyn, LXIX, 1989, s. 45-59.

Schjørring, Jens Holger, „Grundtvig og en gudstjenstlig teologi Dansk teologisk Tidsskrift, L, 1987, s. 289-301.

Schjørring, Jens Holger, »Ordet og Myten - og deres anvendelse i Grundtvigs salmer«. Under Guds Ord, nr. 301, 1989, s. 1-4. 
Simon, Erica, »Afrika og Grundtvig«. Dansk Udsyn, LXVIII, 1988, s. 360-66. (Om »Négritude-bevægelsen «.)

Simon, Erica, »Grundtvig og det franske skolesystem «. Tidsskriftet Den frie Larerskole (Ollerup), XXXVII:1, 1989, s. 4-7.

Simon, Erica, »N. F. S. Grundtvig. En dansker med verdensomspændende betydning «. Dansk Udsyn, LXIX, 1989, s. 186-202. (Foredrag på G-seminar i Köln; cf. Hans Henningsen, smst., s. 300-02.)

Skovmand, Roar, »Grundtvigs højskoletanker og Grundtvigs Højskole«. Dansk Udsyn, LXVI, 1986, s. 216-28.

Slumstrup, Finn, »Grundtvigs oplysningstanker«. Uddannelse, XXIII, 1990, s. 240-47.

Thaning, Kaj, »Grundtvig's Conception of Christianity«/»Grundtvig's View of Culture «. Church and Life (Askov, Minnesota), XXXIV, 1985, nr. 2, s. 9-11, og nr. 3, s. 9-12. $\left(^{*}\right)$

Thaning, Kaj, »Fra Grundtvigs sidste hjem«. Vartovbogen, 1987, s. 97 115.

Thaning, Kaj, »Enkens søn fra Nain«. Grundtvig-Studier, 1989-1990, s. 32-45. (Engelsk resumé, s. 319-23.)

Thodberg, Christian, „Grundtvigs skovoplevelse i 1811 og prædikenerne over Peters fiskedræt i tiden, der fulgte«. Grundtvig-Studier, 1986, s. 11-55. (Engelsk resumé s. 96-99.) (Optrykt 1989, cf. ovf. u. III.)

Thodberg, Christian, »To oversete Grundtvig-salmer «. Under Guds Ord, nr. 284, 1987, s. 1-4. (Om »Smuler under Herrens bord « og »Kistelagt var enkesønnen «.)

Thodberg, Christian, „Guds Søn kom selv til Jordans Flod «. Dansk Kirkesangs årsskrift, 1985-88 [udk. 1989], s. 65-80. (Luther-salme oversat og kommenteret med stadigt henblik på G’s 1836- og 1837versioner.)

Thodberg, Chr., »Vejen tilbage. Et Jerusalem-motiv hos Grundtvig «. Dansk teologisk Tidsskrift, LII, 1989, s. 287-307. 
Thyssen, Anders Pontoppidan, „Vort forhold til andre kirkesamfund historisk belyst «. Praesteforeningens Blad, LXXIX, 1989, s. 17-23. (Optrykt 1989 , cf. ovf. u. IV.)

Torm, Axel, »Grundtvig og Israel «. Dansk teologisk Tidsskrift, XLVII, 1984, s. 244-64.

True, Henrik, »Grundtvig og Luther «. Dansk Kirketidende, CXXXVIII, 1986, s. 349-56.

Tøjner, Poul Erik, »Herskab og tjenestefolk. Et rapsodisk notat om Ejvind Larsens levende ord «. Kredsen, LII:2, 1986, s. 67-74. (Om Gbibliografiens $\mathrm{nr}$. 81.)

Vogel, Norbert, »Grundtvigs Schulgedanken aus deutscher Sicht«.

Grundtvig-Studier, 1989-1990, s. 157-86. (Dansk resumé, s. 327-29.)

Wigh-Poulsen, Henrik, »Grundtvig, kunsten og naturen«. Fønix, XIII, 1989, s. $172-84$.

Wåhlin, Vagn, »Grundtvigs økonomiske tænkning «. Grundtvig-Studier, 1989-1990, s. 246-303. (Engelsk resumé, s. 331.)

Yde, Henrik, »Lenin og Grundtvig - hånd i hånd «. Humaniora, V:1, 1991, s. 28-30. (Foromtale af bog om Martin Andersen Nexøs sammentænkning af marxisme og grundtvigianisme, Det grundtvigske $i$ Martin Andersen Nexøs liv.)

Ægidius, Jens Peter, »Grundtvig, mytologien og højskolen «. Tidsskriftet Den frie Larerskole (Ollerup), XXIX, 1981, s. 3-16.

Aarsbo, Jens, „Sprogmesteren. Om Grundtvigs Sprog og Salmedigtning «. Hymnologiske Meddelelser, XVI, 1987; s. 115-73. (Afsnit af utrykt afhandling om sangværket; afsluttet 1940.)

\section{SEKUNDÆRLITTERATUR. AVISARTIKLER}

Albertsen, Leif Ludwig, »Ned med Grundtvig?« Jyllands-Posten 26.8. 1989. (Om G’s syn på udenadslære.) 
Balslev-Clausen, Peter, »Ingemann og Grundtvig«. Kristeligt Dagblad 27.5.1989.

Billeskov Jansen, F. J., »To verdener eller én«. Politiken 8.12.1990. (Om litteratur vedr. G og Søren Kierkegaard.)

Bjørn, Lars Thorkild, »Havde jeg tjent en tønde guld «. Frederiksborg Amts Avis 16.2.1988; Flensborg Avis 1.3.1988. (Om »Skolen for Livet og Academiet i Soer «.)

Brandt-Nielsen, E., »At sige verden ret farvel - «. Kristeligt Dagblad 24.2.1987. (Om G's begravelsessalmer.)

Brandt-Nielsen, E., »Uretfærdigt sat i skygge«. Kristeligt Dagblad 4.6. 1987. (Om Lise Blicher.)

Brovst, Bjarne Nielsen, »Grundtvigs store sorg «. Frederiksborg Amts Avis 9.3.1987. (Om Marie Toft, død 1854.)

Christensen, Bent, »Var Grundtvigs kirkepolitik en tragedie? « Kristeligt Dagblad [Teologisk Forum] 27.1.1986. (Om Kaj Thanings G-fortolkning.)

Christensen, Johs. H., »Poesiens underfulde magt«. Kristeligt Dagblad [Teologisk Forum] 14.12.1987. (Om »Velkommen igen, Guds engle små «.)

Elbek, Jørgen, »Frederik og Ulrikke«. Information 20.1.1987. (Optrykt 1989, cf. ovf. u. IV.)

Elbek, Jørgen, »Tårers magt«. Information 30.3.1991. (Om G’s »græske« vækkelse.)

Gleerup, Jørgen, »Salmen og poesien«. Kristeligt Dagblad 21.8.1986. $(\mathrm{Om} » \mathrm{O}$ dejlige land $\ll$.)

Gregersen, Niels Henrik, „Grundtvig som prædikant og poet«. Information 7.7.1989. (Anmeldelse af G-udgivelser af Jens Brun og Christian Thodberg.)

Jensen, Johannes, »Med Grundtvig på kuskesædet og med Thorvaldsen og Oehlenschläger i kareten«. Kristeligt Dagblad 6.4.1985. 
Korsgaard, Ove, »Grundtvig som bokser«. Information 23.10.1986.

Klejs, Johan, »Fortvivlelsens poesi«. Kristeligt Dagblad 19.5.1989. (Om »Som tørstige hjort monne skrige«.)

Kvist, Vagn, [Artikelserie om G-salmer.] Vestkysten 20.8., 10.9. og 24.12.1983, 28.1., 3.3., 14.4. og 23.6.1984, 26.1., 2.3., 27.4., 25.5., 24.8., 28.9., 30.11. og 21.12.1985, 15.3., 26.4., 26.7., 30.8. og 27.12.1986, 31.1., 18.4., 30.5., 4.7., 31.10. og 12.12.1987, 9.1., 13.2., 12.3., 14.5. og 11.6.1988, 12.5., 23.6. og 29.12.1989, 9.2., 8.6., 20.7., 5.10. og 14.12.1990.

Kaalø, Sten, „At natten hun er nu omme!« Kristeligt Dagblad 15.8.1986. (Om »Den signede $\mathrm{dag}$.)

Larsen, Thorkild Mads, »Skolen for alle«. Kristeligt Dagblad 6.8.1990.

Lorentzen, Inge, »Dejlig er den himmel blå. En vejledning for dem, der vil undervise børn i hjem, skole og klubber«. Kristeligt Dagblad 3.1.1989.

Møllehave, Johannes, »Hyttefesten«. Fyens Stiftstidende 24.12.1987. (Om "Det kimer nu til julefest $\ll$.)

Nägele, Horst, »Grundtvigs Europa-tanker«. Kristeligt Dagblad 20.12. 1989.

Nielsen, Michael, »Grundtvig og det mellemkirkelige«. Kristeligt Dagblad 29.3.1988.

Pedersen, Jens, »Julesalmen og gråden «. Fyens Stiftstidende 24.12.1986. (Om »Velkommen igen, Guds engle små «.)

Salomonsen, Ejlif, „Da Grundtvig gav os det levende foredrag «. Kristeligt Dagblad 31.5.1988. (150-året for »Mands Minde«-foredragene.)

Simonsen, Vagn L., "Når der stryges i Grundtvig «. Kristeligt Dagblad 10.2.1989. (Om en strofe i »Et barn er født i Betlehem «; cf. hertil Kaj Thaning, »Grundtvig strøg ord i salmen«, smst. 2.3.1989.)

Slumstrup, Finn, »Grundtvig og Hørup var enige om ét: Kys frøen!« Information 23.9.1989. 
Thaning, Kaj, »Da Gudsriget blev nutid for Grundtvig«. Kristeligt Dagblad 30.3.1988. (Om »Velkommen igen, Guds engle små«.)

Thodberg, Christian, »Rimfrosten, der daterer Grundtvigs velkomstsalme«. Kristeligt Dagblad 22.12.1987. (Om »Velkommen igen, Guds engle små «.)

\section{VARIA}

Fagerlund, Michael, »Frihed på dagsordenen. Grundtvigs politiske ideer kan bruges til at give dansk liberalisme en saltvandsindsprøjtning, mener undervisningsminister Bertel Haarder «. Vestkysten 12.3.1988. (Interview; også i: Morgenposten 13.3.1988; cf. hertil Henning Tjørnehøj, »Grundtvigs sociale blindhed «, Fyens Stiftstidende 12.4.1988.)

„Fragen aus Dänemark an die Universitäten Deutscher Zunge. Ein unvollendeter Entwurf «. Grundtvig-Studier, 1988, s. 17-30. (Dansk oversættelse s. 31-43.)

„Grundtvig om folkekirken på Den grundlovgivende Rigsforsamling i 1849«. Grundtvig-Studier, 1987, s. 11-15.

Høirup, Henning, „Steen Johansen, 18. oktober 1908 - 9. februar $1987 \ll$. Grundtvig-Studier, 1987, s. 7-10.

Jepsen, Signe, »Et besøg på The Grundtvig Institute i Nigeria«. Højskolebladet, 1990, s. 92-94.

Larsen, Bjarke, »Grundtvig lever og har det godt - i Nigeria«. Information 29.10.1990.

Litteratur 2: 1780-1870. Redigeret af Lise Ettrup, Jens Anker Jørgensen og Knud Michelsen. 1983. S. 54-59 (af "Dagbogsoptegnelser 1803$05 \ll$ ), 127-28 (»Nu skal det aabenbares«), 143-45 (»Kirken det er et gammelt Huus«), 175-78 (»Sang i det grønne «, »At sige Verden ret Farvel«), 221-27 (af »Dansk Rigsdags-Tale imod den saakaldte almindelige Værnepligt«).

Overblik. I-II. Redigeret af Jørn Ørum Hansen, Erik H. Madsen og Erik A. Nielsen. 1989-90. I: Tradition. Linier og forvandlinger, s. 56-59 (af »Nordens Mythologi«), 60-61 (af »Mands Minde«), 387 (»Oplysning«); II: Gennembrud. Modernitet og fornyelser, s. 64-66 (»De 
Levendes Land«), 178-79 (af »Er Troen virkelig en Skole-Sag«), 191 (»Tag det sorte Kors fra Graven«).

Romantik. På sporet af det moderne individ 1800-1840. En antologi. Redigeret af Gert Emborg og Jørgen Aabenhus. 1987. S. 201-02 (»Duggen «).

Raahauge, Anders, »Et center for Grundtvig«. Kristeligt Dagblad 16.2. 1990. (Interview med Christian Thodberg om Center for Grundtvigstudier, Aarhus Universitet.)

Schjørring, Jens Holger, "Poul Georg Lindhardt in memoriam«. Grundtvig-Studier, 1988, s. 7-16.

Schjørring, Jens Holger, Christian Thodberg \& Anders Pontoppidan Thyssen, "Center for Grundtvigstudier - en introduktion «. Praesteforeningens Blad, LXXX, 1990, s. 41-49. (Cf. Nyhedsbrev [udg. af Det teologiske Fakultet, Aarhus Universitet], VIII:1, 1990, s. 15-18.)

»Skabt i Guds Billede. En lidet kendt udredning af Grundtvig fra 1814«. Grundtvig-Studier, 1986, s. 7-10. (Optryk af »Kort Begreb af Verdens Krønike, betragtet i Sammenhæng«, 1814, s. 14-19.)

Spurvesol. II. Redigeret af Peter Kaspersen, Jens Skovholm og Ivan Z. Sørensen. 1989. Indledningen s. 28-29, tekstudvalget s. 47-52 (»Indskrivten paa Oddens Mindest $\emptyset t t e «, ~ » S u t t u n g s$ Mjød«, »Folkeligheden «).

Steens, Jørgen, »Maja og Danmark og tiptipoldefar «. Kristeligt Dagblad 21.3.1990. (Interview med 20-årig G-efterkommer.)

»Synet. Et ungdomsdigt af Grundtvig«. Grundtvig-Studier, 1989-1990, s. 9-15.

Grundtvig-Studier. 1986-årg.: Anm. af Holger Jepsen, Proesteforeningens Blad, LXXVIII, 1988, s. 378-80. 1987-årg.: Anm. af Poul Engberg, Kristeligt Dagblad 3.11.1988, Niels Henrik Gregersen, Information 9.1.1989, Jakob Fløe Nielsen, Proesteforeningens Blad, LXXIX, 1989, s. 545-46. 1988-årg.: Anm. af Poul Engberg, Kristeligt Dagblad 5.1.1990 (hvortil debat: William Michelsen, 15.1.; Poul Engberg, 22.1.), Jakob Fløe Nielsen, Praesteforeningens Blad, LXXX, 1990, s. 890-91. 1989-1990-årg.: Anm. af Helge Baden Nielsen, Prasteforeningens Blad, LXXXI, 1991, s. 457-60. 


\section{RETTELSER M.V. TIL GRUNDTVIG-BIBLIOGRAFIEN}

Bibliografien omfatter 88 sider + et indlagt rettelsesblad. Af dette fremgår ikke, at trykkeriet har ombyttet siderne $14 \mathrm{og} 15$. Desuden kan nævnes følgende småting:

Anm.: Gustav Albeck, Grundtvig-Studier, 1986, s. 84-86. (Engelsk resumé s. 103-04.)

Tilføj: Efterskriften optrykt i: Erling Nielsen, Vor mand $i$ Oslo. En tekst-mosaik. 1990. S. 13-24. (»Om forkyndelse og poesi i salmerne «.) En udvidet version indgår i: Erling Nielsen, H. C. Andersen og andre danskere. Oslo, 1974. S. 17-34. (»Danske salmer $\ll$.)

Anm.: Uffe Hansen, Dansk Kirketidende, CXXVII, 1975, s. 6-8.

XII: 1838-39, 1986, 384 s., indledning s. 7-81.

Anm.: Niels Lyhne Jensen, Scandinavian Studies, LVIII, 1986, s. 326-28.

Tilføj: 1983.

Cf. Signe Sandberg, Kirke og Kultur, XC, 1985, s. 148-52.

92 Anm.: Holger Jepsen, Organist-Bladet, L, 1984, s. 147, 14950, 152-53 og 155-57.

233 (i linie 19), læs: 223.

112 Anm.: Arne Hassing, Scandinavian Studies, LXII, 1990, s. 238-40.

206 Tilføj: 2. udg., 1990.

209 Linie 2 udgår.

295 (1827), læs: (1837).

693 Tilføj: Højskolebladet, 1984, s. 169-73 og 184-87. 